\title{
Butterfly Shaped Patch Antenna for 5G Applications
}

\author{
Ribhu Abhusan Panda ${ }^{1}$, Debasish Mishra², Pawan Kumar Nayak ${ }^{3}$, Mihir Panda ${ }^{4}$
}

${ }^{I}$ Department of Electronics and Telecommunication, Veer Surendra Sai University of Technology, Burla, Odisha, India, ribhupanda@gmail.com ${ }^{2}$ Department of Electronics and Telecommunication, Veer Surendra Sai University of Technology, Burla, Odisha, India, debasisuce@gmail.com ${ }^{3}$ Department of Electronics and Communication, GIET, Main Campus (Autonomous), Gunupur, Odisha, India, pawannayak2000@gmail.com ${ }^{4}$ Department of Electronics and Telecommunication, GIET, Main Campus (Autonomous), Gunupur, Odisha, India, mihirpanda88@gmail.com

*Correspondence: Dr. Ribhu Abhusan Panda; Email: ribhupanda@gmail.com

\begin{abstract}
Widely used patch in circular shape has been cut in two semicircular shapes and joined together, arc to arc to same feed in dipolar form, produces a butterfly shape. In this paper each semicircular shapes are remodeled as bi-circular shapes for enhancement of gain so that it can be operated at a frequency of $15 \mathrm{GHz}$ which is applicable for $5 \mathrm{G}$ communication. This antenna is placed on a substrate of FR4epoxy material. The design of the shape is based on the minimum distance of the two extreme arcs of the two parts which becomes the wavelength of the required resonant frequency. This design is compatible with all antenna requirements including S11 plot from which the resonant frequency and return loss have been determined. The software used in HFSS, by which antenna parameters like antenna gain, directivity etc. have been checked. The patch and the ground plane is of same material, copper.
\end{abstract}

Keywords- Butterfly Shape, 5G, FR4-Epoxy, S11, Antenna Gain.

\section{INTRODUCTION}

Between two contrasting shapes of patch antenna, i.e. rectangular and circular, the latter has an advantage as it produces different modes that can be modified. A complete circular shape or semicircular shape produces similar modes of radiation.

\section{ARTICLE INFORMATION \\ Author(s): Ribhu Abhusan Panda, Debasish Mishra, Pawan Kumar Nayak and Mihir Panda Received: September 19, 2020; Published: December 25, 2020; \\ e-ISSN: 2347-470X; Paper Id:IJEER-080301; \\ Citation: https://doi.org/10.37391/IJEER.08030 \\ Webpage-link: http://ijeer.forexjournal.co.in/archive/volume- \\ 8/ijeer-080301.html \\ In this paper two semicircular shapes are joined together in reverse, arc to arc in a dipolar form. Again each part of semicircular shape is modified to form a bi-circular shape. This}

design looks like a butterfly and has been implemented as a microstrip design. This type of antenna design has taken center stage because of its two important characteristics - small size and robust in nature [1]. In this type of antenna, different shaped patches are implemented and have been perfected to operate in microwave range. Among the shapes, circular patches with modified shapes have been presented for wider applications [2][3][4]. Besides circular shape, elliptical shape has also introduced as it produces a slight different modes of vibration. [5]. However the circular shapes can easily be modified in biconvex and biconcave shapes and these designs are implemented for enhancement of gain and bandwidth with an introduction of circular slots in the antenna [6],[7]. These designs have been improvised for applications in 5G. [8]. However remodeling a simple design to a dipolar form can produce double effect. This paper carries a concentrated work on this aspect, so that it can be implemented for $5 \mathrm{G}$ application which has a wide range of frequency [9][10]. This design is specially calibrated to resonant at $15 \mathrm{GHz}$ frequency which is suitable for $5 \mathrm{G}$ applications. Moreover it provides a higher gain and higher directivity compared to other designs.

\section{MATHEMATICAL ANALYSIS FOR ANTENNA DESIGN}

The design of the antenna is remodeled in three step, first a model just like a dipole is executed. Second, two semicircular halves of a circular antenna is joined together in reverse order like a butterfly [11] and third, the shape of each wing is again remodeled as a bi-circular shape [12].Centers of all arcs and joint points are made collinear. To get the resonant frequency of $15 \mathrm{GHz}$, this antenna is so designed that the minimum distance between the two extreme arcs is taken as $20 \mathrm{~mm}$. The patch of thickness is $0.01 \mathrm{~mm}$ placed on a substrate of FR4epoxy dielectric material whose length and breadth are $30 \mathrm{~mm}$ and $42 \mathrm{~mm}$ with height $1.6 \mathrm{~mm}$. The ground plane has same area as of substrate with thickness of $0.01 \mathrm{~mm}$. The feed of width $3 \mathrm{~mm}$ as shown in figure 1 . 


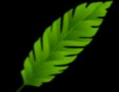 EForR푸}

Open Access | Rapid and quality publishing

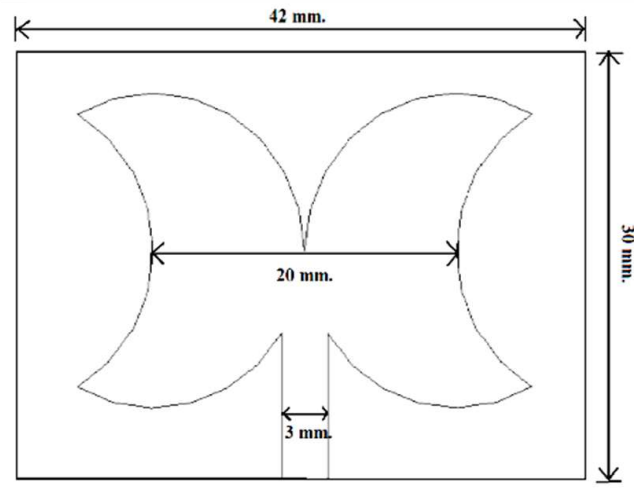

Figure 1: Geometry of bi-circular butterfly patch

The radius of a conventional circular patch is given by

$$
\mathrm{a}=\frac{F}{\left\{1+\frac{2 h}{\pi \varepsilon_{r} F}\left[\ln \left(\frac{\pi F}{2 h}\right)+1.772 \quad \frac{1}{2}\right.\right.}
$$

Effective radius of circular patch [1]

$$
\mathrm{a}_{\mathrm{e}}=\mathrm{a}\left\{1+\frac{2 h}{\pi \varepsilon_{r} a}\left[\ln \left(\frac{\pi a}{2 h}\right)+1.7726\right]\right\}^{\frac{1}{2}}
$$

Effective dielectric constant of substrate: $\left(\varepsilon_{e}\right)$

$$
\varepsilon_{e}=\frac{1}{2}\left[\varepsilon_{\mathrm{r}}+1+\left(\varepsilon_{\mathrm{r}}-1\right)\left(1+\frac{12 \mathrm{~h}}{\mathrm{~W}}\right)^{-1 / 2}\right]
$$

The resonant frequency of a circular patch is given by

$$
f_{r}=\frac{v_{0}\left(\chi_{m n}^{\prime}\right)}{2 \pi a_{e} \sqrt{ } \epsilon_{r}}
$$

$\mathrm{V}_{0}=$ velocity of light in free space.

$\chi_{m n}^{\prime}$ is zeroes of derivatives of Bressels' function with $\mathrm{m}$ and $\mathrm{n}$ are the modes of vibration.

For conventional circular patches $\mathrm{m}=1, \mathrm{n}=1$ and $\chi_{m n}^{\prime}=1.841$

For a design made by two semicircular shapes joined in dipolar form [11] the resonant frequency becomes 6.967 times this
International Journal of Electrical and Electronics Research (IJEER) Research Article | Volume 8, Issue 3 | Pages 32-35 | e-ISSN: 2347-470X

value. This is because the value of ' $m$ ' changes to 10 to produce feasible mode in the cavity.

Again when the semicircular shapes [12] are chiseled in two bicircular form the frequency increases to 2.42 times (minimum) for $n=1$ and 8.18 times (maximum) for $n=4$ of the original circular form. Here both alterations are incorporated. So the mode of resonance that can be produced is 7.27 times the original. This is comparatively displayed in Table 1 .

Table 1. Comparison between different shapes

\begin{tabular}{|c|c|c|c|c|c|}
\hline $\begin{array}{c}\text { Refere } \\
\text { nce }\end{array}$ & $\begin{array}{c}\text { Shape of } \\
\text { the Patch }\end{array}$ & $\begin{array}{c}\text { Modes of } \\
\text { Vibration } \\
\mathbf{m , n}\end{array}$ & $\chi_{\mathbf{m n}}^{\prime}$ & $\begin{array}{c}\text { Resonant } \\
\text { frequency } \\
\text { (GHz) }\end{array}$ & $\begin{array}{c}\text { Antenna } \\
\text { Gain } \\
\text { (dB) }\end{array}$ \\
\hline $\begin{array}{c}\text { Ref.[ } \\
11]\end{array}$ & $\begin{array}{c}\text { Semicircula } \\
\text { r Butterfly }\end{array}$ & 11,1 & 12.83 & 14.58 & 1.74 \\
\hline $\begin{array}{c}\text { Ref } \\
{[12]}\end{array}$ & Bi-Circular & 1,4 & 13.32 & 15.18 & 3 \\
\hline $\begin{array}{c}\text { Ref[ } \\
13]\end{array}$ & $\begin{array}{c}\text { Circular/se } \\
\text { micircular }\end{array}$ & 1,1 & 1.84 & 2.09 & 2.1 \\
\hline $\begin{array}{c}\text { This } \\
\text { Work }\end{array}$ & $\begin{array}{c}\text { Bi-Circular } \\
\text { Butterfly }\end{array}$ & 11,4 & 25 & 15.24 & 4.01 \\
\hline
\end{tabular}

\section{RESULTS}

By the software HFSS, the antenna parameters like retirn loss, antenna gain, surface current distribution have been studied, the details are given in figure 2 to figure 6.

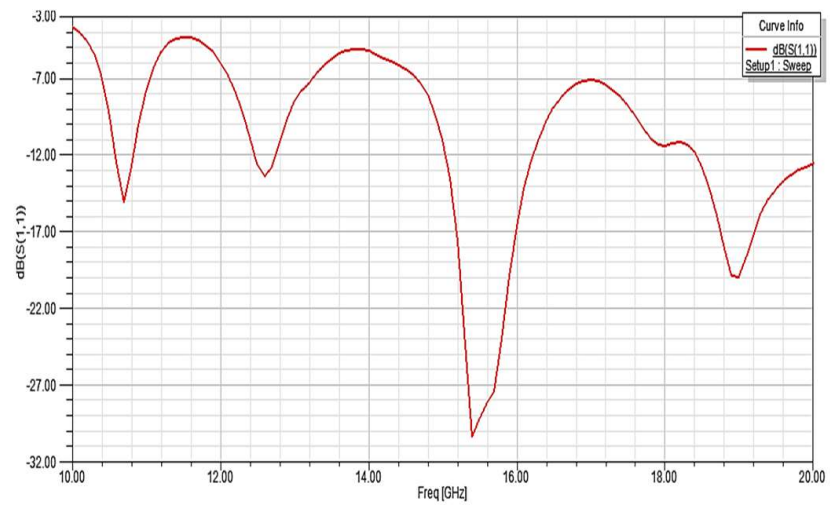

Fig 2: S-Parameter

The impedance matching between source and load is defined by VSWR. It stands for voltage standing wave ratio. Ideally VSWR must be 1, For the proposed patch antenna VSWR is found to be 1.06. The VSWR curve has been shown in Fig. 3 


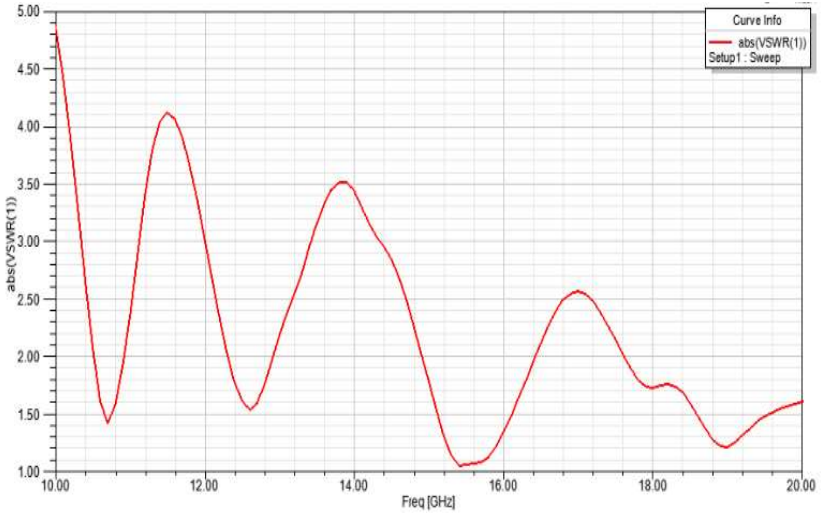

Fig 3: VSWR

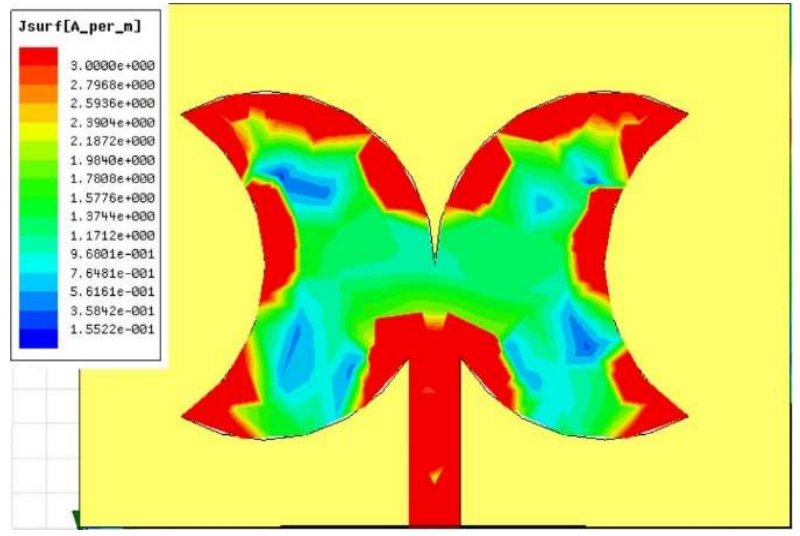

Fig. 4. Current Desnity

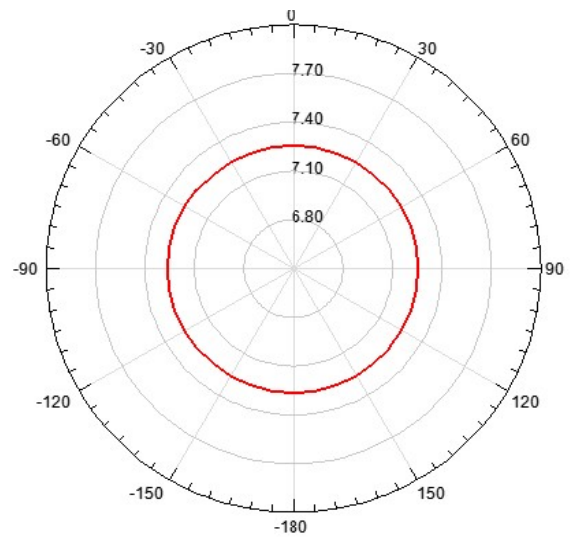

Fig. 5. Peak Directive

The ratio of radiated power to the accepted power from the transmitter is known as radiation efficiency. The radiation efficiency of the proposed patch antenna has been found 0.47 as shown in the Fig. 5.

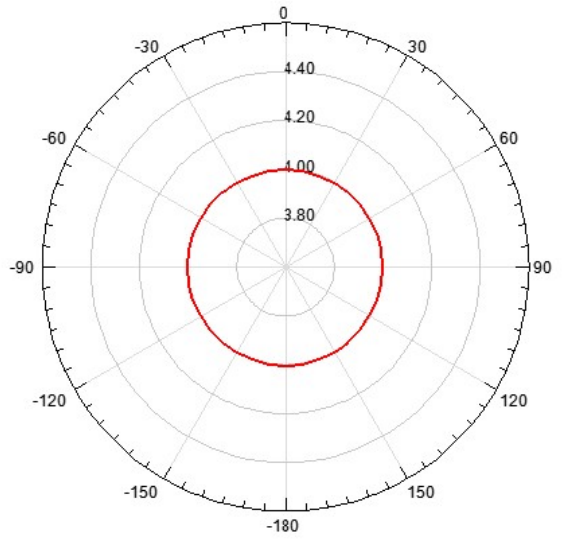

Fig: 6 Peak Gain

\section{CONCLUSION}

This bi-circular butterfly shaped patch is more efficient as compared with other antennas with similar shaped patches .Along with the usual microstrip antenna parameters, this model excels in all other characteristics with antenna gain of $4.01 \mathrm{~dB}$ which is suitable for $5 \mathrm{G}$ application.

\section{REFERENCES}

[1]. Balanis, C.A., "Antenna Theory - Analysis and Design", John Wiley \& Sons, Inc 1997.

[2]. Sung, YJ, Kim YS. Circular polarised microstrip patch antennas for broadband and dual-band operation. Electronics Letters, 2004; 40:9 p. $520-521$

[3]. Guo, Y.J.; Paez, A.; Sadeghzadeh, R.A.; Barton, S.K., "A circular patch antenna for radio LAN's," Antennas and Propagation, IEEE Transactions on, vol.45, no.1, pp.177- 178, Jan 1997.

[4]. H.Iwasaki, "A circularly polarized small-size microstrip antenna with a cross slot," IEEE Trans. Antennas Propagat. Vol.44, pp.1399-1401, Oct.1996.

[5]. Panda R.A., Mishra S.N., Mishra D. (2016) Perturbed Elliptical Patch Antenna Design for $50 \mathrm{GHz}$ Application. In: Satapathy S., Rao N., Kumar S., Raj C., Rao V., Sarma G. (eds) Microelectronics, Electromagnetics and Telecommunications. Lecture Notes in Electrical Engineering, vol 372. Springer, New Delhi. https://doi.org/10.1007/97881-322-2728-1_47

[6]. Panda R.A., Mishra D., Panda H. (2018) Biconcave Lens Structured Patch Antenna with Circular Slot for Ku-Band Applications. In: Satapathy S., Bhateja V., Chowdary P., Chakravarthy V., Anguera J. (eds) Proceedings of 2nd International Conference on Micro-Electronics, Electromagnetics and Telecommunications. Lecture Notes in Electrical Engineering, vol 434. Springer, Singapore. https://doi.org/10.1007/978981-10-4280-5_8

[7]. Beale Cedric Dehos, Jose Luis Gonzalez, Antonio De Domenico, Dimitri Ktenas and Laurent Dussopt. 2014. "Millimeter-Wave Access and Backhauling: The Solution to the Exponential Data Traffic Increasein 5G Mobile Communications Systems?" IEEE Communications Magazine, September, pp. 88-94. 


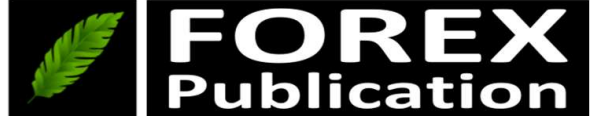

Open Access | Rapid and quality publishing
International Journal of Electrical and Electronics Research (IJEER) Research Article | Volume 8, Issue 3 | Pages 32-35 | e-ISSN: 2347-470X

[8]. Jian Qiao, XueminShen, Jon W. Mark, Qinghua Shen, Yejun He and Lei Lei. 2015. "Enabling Device-to-Device Communications in MillimeterWave 5G Celluar Networks." IEEE Communications Magazine, January, pp. 209-214.

[9]. Ahmed Lyanda Sulyman, AlMuthana T. Nassar, Mathew K. Samimi, George R. Mac Cartney Ji, Theodore S. Rappaport and Abdulhameed Alsanie. 2014. "Radio Propagation Path Loss Models for 5G Cellular Networks in the $28 \mathrm{GHz}$ and $38 \mathrm{GHzMillimeter-Wave} \mathrm{Bands."} \mathrm{IEEE}$ Communications Magazine, September, pp. 78-85.

[10]. R. A. Panda and D. Mishra, "High Directional CPW fed Butterfly Shaped Patch Antenna for WiGig Networks," 2019 3rd International conference on Electronics, Communication and Aerospace Technology (ICECA), Coimbatore, India, 2019, pp. 1081-1084, doi: 10.1109/ICECA.2019.8821886.

[11]. Panda, R.A., Mishra, D. Efficient Design of Bi-circular Patch Antenna for 5G Communication with Mathematical Calculations for Resonant Frequencies. Wireless Pers Commun 112, 717-727 (2020).

[12]. Ashish Singh, J.A. Ansari, Kamakshi, Mohammad Aneesh, Saiyed Salim Sayeed,L-strip proximity fed gap coupled compact semi-circular disk patch antenna, Alexandria Engineering Journal, Volume 53, Issue 1, 2014, Pages 61-67. 